\title{
Estudo exploratório sobre as concepções e estratégias de intervenção de professores em face do bullying escolar
}

\author{
Jorge Luiz da Silva \\ Wanderlei Abadio de Oliveira \\ Marta Angélica lossi da Silva \\ Universidade de São Paulo, Ribeirão Preto - SP - Brasil \\ Beatriz Oliveira Pereira \\ Universidade do Minho, Ciec - Braga - Portugal \\ Sálua Cecilio' \\ Universidade de Uberaba, Uberaba - MG - Brasil
}

\begin{abstract}
Resumo: Este estudo qualitativo objetivou identificar o conhecimento de professores do $6^{\circ}$ ano do ensino fundamental sobre o bullying e as intervenções por eles desenvolvidas. Participaram dez professores, e os dados foram coletados por meio de questionários estruturados. As análises seguiram os pressupostos da análise de conteúdo, em sua modalidade temática. Verificou-se, nos resultados, uma compreensão insuficiente dos professores que incidia na capacidade de identificação e na maneira como intervinham nos episódios de bullying entre os alunos. Depreende-se que o bullying constitui um aspecto importante a ser trabalhado com os professores, considerando a proximidade com a questão e o papel essencial que podem assumir no seu enfrentamento.
\end{abstract}

Palavras-chave: violência escolar; bullying; professor; relações interpessoais; desenvolvimento psicossocial.

\section{AN EXPLORATORY STUDY OF TEACHERS' CONCEPTIONS AND INTERVENTION STRATEGIES IN THE FACE OF SCHOOL BULLYING}

\begin{abstract}
This qualitative study's aim was to identify the knowledge of 6th grade teachers concerning bullying and interventions they developed. A total of ten teachers were included and data were collected using structured questionnaires. The analyses followed the assumptions of thematic content analysis. The results revealed that teachers had a poor understanding of the problem, which affected their ability to identify and intervene in bullying situations faced by students. It appears that bullying is an important aspect to be discussed with teachers considering their proximity to the problem and the essential role they can play helping students to overcome it.
\end{abstract}

Keywords: school violence; bullying; teacher; interpersonal relationships; psychosocial development.

${ }^{1}$ Endereço para correspondência: Sálua Cecilio, Departamento de Educação, Universidade de Uberaba, Avenida Nenê Sabino, 1.801, bloco 2X16, sala 2X16E, Universitário, Uberaba - MG - Brasil. CEP: 38055-550. E-mail: salua.cecilio@uniube.br. 
ESTUDIO EXPLORATORIO SOBRE LAS CONCEPCIONES Y ESTRATEGIAS DE INTERVENCIÓN DE PROFESORES FRENTE AL BULLYING ESCOLAR

\begin{abstract}
Resumen: Este estudio cualitativo tuvo por objetivo identificar el conocimiento que tienen los profesores de $6^{\circ}$ año de enseñanza primaria sobre el bullying y las intervenciones desarrolladas por ellos. Participaron diez profesores y los datos fueron colectados a través de cuestionarios estructurados. Los análisis siguieron las bases del análisis de contenido en su modalidad temática. En los resultados se comprobó una comprensión insuficiente de los profesores que se enfocaban en la capacidad de identificación y en la manera como intervenían en los episodios de bullying entre los alumnos. Se deduce que el bullying constituye un aspecto importante para ser trabajado junto a los profesores, considerando la proximidad con la cuestión y el rol esencial que pueden asumir al enfrentarlo.
\end{abstract}

Palabras clave: violencia escolar; bullying; profesor; relaciones interpersonales; desarrollo psicosocial.

A violência escolar é uma realidade que atinge uma parcela significativa de crianças e adolescentes, transformando as instituiç̧̃̃es educacionais em territórios pouco seguros, e as relações que nelas se desenvolvem vão sendo esboçadas a partir de novas configurações assinaladas muitas vezes por angústia, sofrimento e medo (Skrzypiec, Slee, Murray-Harvey, \& Pereira, 2011). Nesse cenário, o bullying tem se destacado como um problema importante a ser investigado e enfrentado. Conceitualmente, constitui um tipo de violência interpessoal caracterizado pela intimidação entre pares. Representa qualquer comportamento - ou atitude - agressivo intencional, repetitivo e realizado dentro de uma relação desigual de poder entre vítimas e agressores (Ahtola, Haataja, Kärnä, Poskiparta, \& Salmivalli, 2012; Lisboa, Braga, \& Ebert, 2009; Boulton, Woodmansey, Williams, Spells, Nicholas, Laxton, Holman, \& Duke, 2012).

Trata-se de um fenômeno preocupante tanto pelo seu crescimento quanto por atingir faixas etárias iniciais, relativas aos primeiros anos de escolaridade, e pelo sofrimento que impõe aos sujeitos envolvidos, sejam como vítimas, agressores ou espectadores (Olweus, 2013). Estudos realizados internacionalmente apontam para níveis elevados desse fenômeno no contexto escolar. Em Portugal, uma investigação desenvolvida com 4.092 alunos verificou que $37 \%$ deles estavam envolvidos em situações de bullying (Pereira, Mendonça, Neto, Valente, \& Smith, 2004). Um estudo transcultural identificou uma média de aproximadamente $40 \%$ em 28 países (Due, Holstein, Lynch, Diderichsen, Gabhain, Scheidt, \& Currie, 2005). No Brasil, uma pesquisa nacional realizada em 2009 identificou um envolvimento de 30,8\% em 60.973 escolares participantes do estudo (Malta, Silva, Mello, Monteiro, Sardinha, Crespo, \& Porto, 2010).

Os dados fornecidos pela literatura, além de sinalizarem a amplitude dessa problemática nos contextos escolares, reforçam a pertinência da adoção de estratégias de intervenção e prevenção, destacando a detecção precoce do bullying e o estímulo a comportamentos voltados para o estabelecimento de uma cultura de não violência (Fisher, 2010), especialmente porque a ocorrência desse fenômeno está associada à manifestação de diversos desajustes psicossociais que interferem na qualidade de vida e no rendimento escolar dos alunos. Identifica-se que, de maneira geral, as vítimas e os espectadores sentem medo constante, insegurança, ansiedade e retraimento social. 
Além disso, têm baixo desempenho escolar, autoestima reduzida, sentimentos negativistas e depressão. Em casos mais graves, podem cometer suicídio. Os agressores, em seu turno, podem se envolver em situações de violência doméstica, uso e abuso de drogas e prática de atos infracionais (Fung, 2012).

Em termos de classificação, o bullying pode ser diferenciado em três tipos: físico, verbal e indireto. O físico se refere a agressões corporais, o verbal consiste em insultos e/ou apelidos pejorativos que ressaltam características pessoais negativas da vítima, e o tipo indireto corresponde a condutas indesejáveis e antissociais, como excluir alguém do grupo de pares (Olweus, 2013). É importante destacar que os três tipos se manifestam por agressões que ocorrem repetidamente e sem motivação aparente.

Pesquisas recentes alertam para a necessidade de reconhecer se os alunos são vítimas de somente um tipo de agressão ou de diversos, pois se verifica que é especialmente neste último caso que apresentam maior dificuldade em solicitar ajuda e lidar por si mesmos com os ataques que sofrem (Skrzypiec et al., 2011). Depreende-se do quadro apresentado a necessidade de os professores conhecerem a diversidade de comportamentos que constituem as agressões que são praticadas e compreenderem, em maior profundidade, as características do bullying para que possam lidar melhor com ele.

No contexto das agressões, identifica-se uma definição de papéis que, em geral, possibilita uma diferenciação clara entre vítimas e agressores, embora também se identifique a existência de um grupo menor composto por alunos que agridem, mas que também são intimidados. Este corresponde ao grupo de maior complexidade no tocante à identificação e intervenção, por apresentar ao mesmo tempo uma dupla situação. Nesse caso, os professores devem estar bem (in)formados para que possam perceber as nuances apresentadas por esse grupo específico e lidar adequadamente com elas (Ahtola et al., 2012).

Os picos de vulnerabilidade ao bullying se localizam nos períodos de transição no ensino (Olweus, 2013) que, especificamente, na realidade brasileira, correspondem às mudanças de ciclo, do $5^{\circ}$ ao $6^{\circ}$ ano do ensino fundamental e o do $9^{\circ}$ ano para a $1^{a}$ série do ensino médio. As agressões podem ocorrer em diferentes locais da instituição escolar ou no caminho de casa para a escola. Todavia, a sala de aula é o local em que as agressões são mais passíveis de ocorrer (Fisher, 2010; Rech, Halpern, Tedesco, \& Santos, 2013). Em tal contexto, os professores desempenham um papel fundamental na gestão e prevenção de conflitos entre os alunos. Entretanto, nem sempre conseguem identificar as situações mais sutis, pois as manifestações ocorrem, na maioria das vezes, de forma discreta e oculta ou, mesmo quando percebem essas ou outras ocorrências mais evidentes, decidem não intervir, seja por considerarem as agressões como comportamentos inofensivos, típicos da idade, ou por não se sentirem suficientemente preparados para lidar com as situações ocorridas (Fung, 2012).

Alguns estudos realizados nos Estados Unidos já investigaram o modo como os professores identificam o bullying e quais estratégias de intervenção se utilizam (Tropp-Gordon e Ladd, 2013; Yoon \& Kerber, 2003). Evidenciaram que os professores não 
percebiam em que medida o bullying afetava os alunos, por não compreenderem adequadamente os aspectos atinentes à sua manifestação nem a sua gravidade. No tocante às intervenções que realizavam, se destacavam a orientação aos alunos para resolverem os seus problemas por conta própria, para evitarem contato com os agressores e para as vítimas se autodefenderem das agressões. Também se mostravam mais propensos a intervirem nos casos por eles classificados como apresentando maior gravidade, isto é, aqueles que envolviam agressões de natureza física.

Na realidade nacional, uma pesquisa divulgada em 2013 pelo Sindicato dos Professores do Ensino Oficial do Estado de São Paulo (Apeoesp) sobre a percepção de 1.400 professores da rede estadual de ensino de São Paulo acerca da violência nas escolas, evidenciou visões pontuais e incompletas sobre essa problemática. Para $12 \%$ do grupo amostral, violência escolar seria o bullying, especificamente, e para $62 \%$ seria agressão verbal e xingamento, seguidos por agressão física (43\%). Esse dado, analisado em comparação com a identificação dos professores de episódios de violência, demonstra a fragilidade da compreensão e do domínio teórico que influenciam a percepção por eles apresentada acerca do bullying em si, pois $60 \%$ afirmaram ter conhecimento sobre casos desse fenômeno na escola (Apeoesp, 2013).

A partir dos conhecimentos pessoais sobre o bullying, os professores poderão estruturar as intervenções que empreenderão em sala de aula, as quais influenciarão o comportamento dos alunos, de modo que sejam capazes de dar fim às agressões ou agravar a ocorrência, quando as intervenções se apresentarem inadequadas. Assim sendo, depreende-se que as especificidades das agressões praticadas exigem o domínio de conhecimentos mais amplos e diversificados, com vistas ao êxito no reconhecimento das características essenciais que definem o fenômeno e na realização de intervenções que realmente deem fim à ocorrência dele (Boulton et al., 2012).

Nesse panorama, o presente estudo assumiu por objeto de estudo o bullying escolar a partir da perspectiva de professores do ensino fundamental. Trata-se de uma investigação sobre como eles identificam as situações desse fenômeno na sala de aula e intervêm nelas. Esses aspectos são apontados pela literatura científica como relevantes para o enfrentamento do problema, em função de os professores estabelecerem contato mais direto com os alunos, o que Ihes possibilita a realização de intervenções imediatas na ocorrência das agressões. A identificação eficaz das situações de bullying também desestimula a ocorrência, prevenindo igualmente o surgimento de casos novos. Não obstante a importância que apresenta, o papel desempenhado pelos professores na identificação e no enfrentamento do bullying em sala de aula ainda é pouco investigado (Roth, Kanat-Maymon, \& Bibi, 2011), especialmente na realidade nacional.

\section{Método}

Trata-se de estudo exploratório de natureza qualitativa, realizado em uma escola pública da rede municipal de ensino de um município do interior do Estado de Minas Gerais. A escola se localiza em um bairro da periferia da cidade e oferece ensino 
fundamental 1 (período matutino) e 2 (período vespertino), bem como Educação de Jovens e Adultos (EJA) (período noturno). O público atendido totaliza em média 1.200 alunos distribuídos nos três turnos. A escola foi selecionada por apresentar inúmeras situações de violência e bullying.

Participaram da pesquisa dez professores que lecionavam nas turmas de $6^{\circ}$ ano do ensino fundamental, período no qual se localiza um dos picos de vulnerabilidade às práticas de bullying, conforme indica a literatura. Os participantes apresentaram as seguintes características: $80 \%$ eram do sexo feminino e $20 \%$ do sexo masculino. A média das idades foi de 43,7 anos, e o tempo médio de serviço no ensino, de 14,4 anos. Apresentaram por formação inicial os seguintes cursos: Biologia, Filosofia, História, Matemática e Letras. Ainda concernente à formação, quase a totalidade (90\%) possuía pós-graduação lato sensu. Todos faziam jornada dupla de trabalho, lecionando, em média, em duas ou três escolas.

Utilizou-se como técnica de coleta de dados um questionário elaborado pelos pesquisadores que continha questões fechadas e abertas. Num primeiro momento (parte 1 do questionário), caracterizou-se o perfil dos professores participantes do estudo. Em seguida (parte 2 do questionário), investigaram-se o conhecimento que apresentavam referente ao bullying e a percepção deles quanto à ocorrência do fenômeno em sala de aula e à identificação dos atos classificados por eles como bullying. Por fim (parte 3 do questionário), explorou-se a atuação dos professores diante das situações percebidas.

Os dados foram analisados com base nos pressupostos da análise de conteúdo, em sua modalidade temática, que considera as categorias como "rubricas ou classes, as quais reúnem um grupo de elementos (também conhecidos como unidades de registro, no caso da análise de conteúdo) sob um título genérico, agrupamento esse efectuado em razão dos caracteres comuns destes elementos" (Bardin, 2010, p. 117). Para a realização dessa análise, foram observados os seguintes passos: 1. organização de um plano descritivo dos dados (ideias, destaques, diferenças e similaridades nas falas); 2. identificação e agrupamento dos núcleos temáticos; 3. elaboração de categorias analíticas; 4. apresentação dos resultados. As duas categorias analíticas identificadas foram: concepções dos professores que subsidiam a identificação de episódios de bullying e intervenções empreendidas por eles.

As diretrizes da Resolução n. 196/96 para a realização de pesquisas com seres humanos foram observadas em todas as etapas do estudo. O projeto foi previamente protocolado no Sistema Nacional de Informação sobre Ética em Pesquisa Envolvendo Seres Humanos (Sisnep), submetido ao Comitê de Ética Em pesquisa da universidade e aprovado, conforme Parecer n. 031-2010. A realização do projeto foi precedida também pela autorização da Secretaria Municipal de Educação e pela direção da escola. Os professores foram orientados quanto aos objetivos e procedimentos da pesquisa, e, aos interessados, apresentou-se o Termo de Consentimento Livre e Esclarecido (TCLE). Substituíram-se os nomes dos participantes, a fim de preservar as informações referentes à privacidade e ao sigilo da participação. 


\section{Resultados e discussão}

\section{Concepções dos professores que subsidiam a identificação de episódios de bullying}

No que se refere à identificação das agressões praticadas em sala de aula, o papel do professor é estratégico pela proximidade que compartilha com os alunos durante as aulas. Assim, encontra-se em posição de vantagem para a avaliação e o acompanhamento das interações sociais dos alunos durante as aulas. Isso pode constituir uma vantagem extra para a detecção de alunos que apresentem vulnerabilidade pessoal ao bullying e pouco contato social que lhes asseguraria apoio diante de possíveis ataques e agressões, especialmente se os professores possuírem conhecimentos suficientes que Ihes possibilitem reconhecer os principais aspectos e características desse fenômeno. Especialmente porque a maioria dos incidentes é composta por ações indiretas, sutis e não facilmente observáveis (Fung, 2012).

Sumariamente, os professores investigados demonstraram conhecer as principais formas de manifestação do bullying, em termos da natureza das agressões (física, verbal e psicológica), conforme indicaram as respostas: "Agressão verbal ou física" (P9); "Bulinar, mexer, aterrorizar, discriminar" (P1); "Apelidos, discriminação" (P8); "Qualquer tipo de ofensa (verbal ou física)" (P10); "Constrangimentos, apelidos, etc." (P4). Sobre a ocorrência de bullying especificamente na sala de aula, assim como os principais tipos de agressão identificados, os professores citaram: "agressões físicas e verbais" (P2, P4, P5, P6 e P7); "brigas" (P9); "ridicularizações" (P1); "desprezo, ironia, insultos" (P3); "críticas, ameaças" (P7); "ofensas" (P5, P8 e P9); "apelidos" (P10). Nota-se que as manifestações verbais, na percepção dos professores, são uma tônica, por serem também comuns às relações e às brincadeiras dos alunos entre si, nas quais estão se incluem muitas chacotas e implicâncias.

Contudo, os conteúdos expressos nas respostas denotam situações pontuais de violência. Nota-se a ausência de aspectos fundamentais para a compreensão e caracterização do bullying, como: início com motivação velada, caráter intencional das agressões, desequilíbrio de poder entre vítimas e agressores, recorrência dos atos de violência sustentada especialmente pela falta de recursos adequados das vítimas para autodefesa ou pedidos de ajuda (Lisboa et al., 2009; Olweus, 2013). Essa análise evidencia ainda que um conhecimento insuficiente dos aspectos do bullying dificulta a identificação na sala de aula e a diferenciação de outros comportamentos recorrentes no ambiente escolar, tais como brincadeiras e indisciplina, conforme comenta o professor P2: "Eu tenho uma dificuldade em saber até em qual faixa vai o bullying e a brincadeira de mau gosto".

Entretanto, alguns professores sinalizaram não ser a falta de maior domínio teórico e conceitual sobre o fenômeno que dificulta a identificação e a intervenção que empreendem, mas questões relacionadas às exigências direcionadas ao trabalho que executam, por exemplo: "o conteúdo que é cobrado em avaliação" (P3). Malgrado a justificativa, os dados sinalizam que a precisão na identificação, que subsidia intervenções eficazes, não ocorre devido à falta de conhecimentos mais completos. Isso pode 
dificultar ou impedir que situações mais sutis ou as nuances do bullying sejam reconhecidas, correndo-se o risco de serem negligenciadas ou então que o foco seja deslocado para as agressões físicas e verbais de manifestação mais evidente (Kochenderfer-Ladd \& Pelletier, 2008).

Na pesquisa desenvolvida pela Apeoesp (2013), os professores investigados igualmente não apresentaram conhecimentos abrangentes e aprofundados acerca da complexidade do fenômeno, o que pode ser justificado, em parte, pelo fato de este ser um tema de investigação recente na realidade nacional e que somente a partir de alguns anos passou a ser divulgado maciçamente. Depreende-se dos resultados apresentados que os professores possuem noção geral acerca do bullying e desconhecem alguns aspectos considerados fundamentais para a caracterização e identificação dele, o que demonstra que eles precisam de maior domínio teórico e conceitual sobre tal fenômeno e as diversas formas de manifestação.

\section{Intervenções empreendidas pelos professores}

Nos episódios de bullying em sala de aula, as intervenções empreendidas pelos professores são de fundamental importância para o enfrentamento e controle. O isolamento social apresentado pelas vítimas colabora para que não possam contar com o apoio dos pares na defesa delas. Desse modo, os professores e a instituição escolar em sua totalidade necessitam se posicionar diante das agressões praticadas, com vistas ao oferecimento de suporte aos alunos intimidados (Boulton et al., 2012).

Verificou-se que os professores investigados geralmente recorrem à problematização e discussão das agressões por eles presenciadas, envolvendo, nesse processo, a turma em sua totalidade, com vistas à implicação de todos os alunos, e ao mesmo tempo buscando conscientizá-los das consequências negativas dos atos praticados, mediante o oferecimento de informações e esclarecimentos acerca do que tenha acontecido, conforme exemplificado nas respostas dos participantes: "abrir discussão sobre o tema" (P1); "geralmente colocamos o assunto em discussão, averiguando as consequências dos nossos atos" (P6). Esses dados são coerentes com perspectivas apresentadas pelos participantes na pesquisa da Apeoesp (2013), na qual 28\% dos professores destacaram que debates constituiriam a principal medida a ser implantada para redução da violência escolar.

Compete destacar que, no contexto da violência escolar, as reflexões são importantes por oportunizarem a socialização de informações, estimularem formas de pensamento crítico e darem ensejo à aquisição de maior conscientização. Assim, podem ser consideradas como um bom recurso para a diminuição da ocorrência de bullying. Entretanto, considerando a complexidade que reveste as agressões na escola, depreende-se que a reflexão não é suficiente como medida única de enfrentamento por se relacionar mais a aspectos de natureza pessoal. Cada aluno assimilará o conteúdo refletido em níveis diferentes, de acordo com as características que eles apresentem. Consequentemente, nem todos se encontram em condições de, por si mesmos, dar fim 
às agressões, mesmo que saibam ou compreendam que se trata de algo inadequado à boa qualidade das relações na escola.

Abordagens mais diversificadas e complementares entre si têm sido apontadas como mais indicadas para o enfrentamento e controle de situações de violência e bullying escolar (Fisher, 2010; Lisboa, Braga, \& Ebert, 2009; Olweus, 2013). De acordo com Olweus (1994), intervenções mais eficazes dentro da instituição escolar precisam atender a quatro critérios importantes. O primeiro consiste no envolvimento/interesse dos professores e demais funcionários da escola na redução da incidência de bullying. Especificamente no tocante ao professor, esse envolvimento implica maior vinculação com os alunos, no sentido de serem identificados como figuras de referência e dispostos ao oferecimento de ajuda diante de necessidade. Uma maior quantidade de supervisão e proximidade física em relação aos alunos vitimizados também é altamente recomendada, uma vez que isso aumenta a percepção de suporte social, bem como desestimula os agressores a continuar os ataques.

O segundo critério consiste na definição clara de regras que explicitem quais são os comportamentos considerados adequados e na divulgação dessas regras a todos os alunos. A esse respeito, cumpre destacar que, embora seja mais evidente ao entendimento que as formas físicas de bullying representam comportamentos inaceitáveis, as manifestações verbais ou indiretas podem não ser totalmente reconhecidas ou ambíguas em relação se são ou não permitidas. Daí a necessidade de a escola e os professores se posicionarem formalmente no sentido de não tolerar a ocorrência desses comportamentos (Olweus, 1994).

O terceiro critério se refere à supervisão efetiva dos alunos realizada pelos funcionários nos diferentes locais da escola que possam oportunizar a ocorrência de agressões, como pátios e quadra. Isso é particularmente importante porque o bullying tende a ocorrer em locais da escola mais isolados ou que tenham pouca presença de adultos (Ahtola et al., 2012).

O quarto e último critério faz referência à existência e à aplicação de consequências para o bullying e igualmente que os autores sejam devidamente responsabilizados por suas ações pelas autoridades escolares. Em termos de prevenção, a definição clara de regras, bem como a garantia de seu cumprimento, promove não apenas maior organização do ambiente institucional da escola, como também incentiva um aumento da vinculação dos alunos e colabora para a redução de ataques e agressões (Olweus, 1994).

Conforme demonstrado, como fenômeno multideterminado, o bullying requer intervenções que considerem não somente a sala de aula, mas também a variedade de contextos, agentes e circunstâncias vinculados à sua ocorrência. De um ponto de vista mais abrangente, os melhores resultados têm sido obtidos com intervenções articuladas envolvendo escola, professores, alunos e famílias (Fisher, 2010). Internacionalmente, são adotadas diferentes estratégias, como melhoria da gestão de sala de aula, incentivo ao apoio dos pares e participação das famílias, supervisão de adultos nos locais da escola mais favoráveis à ocorrência de agressões, criação de comitê 
escolar de prevenção à violência, oferecimento de espaços institucionais de mediação de conflitos e treinamento de habilidades sociais com os alunos (Ahtola et al., 2012; Boulton et al., 2012).

Ainda sobre o modo de lidar com o bullying, um professor comentou: "logo no início do ano passo algumas regras e normas da escola [...]. Conto histórias sobre bullying e pró́bo os apelidos e a violência" (P5). A explicitação das regras é importante por enviar a mensagem de que a violência e o bullying são comportamentos inadequados, nocivos e que medidas serão tomadas em função de sua ocorrência. Contudo, apenas uma proibição da violência não pode ser considerada como uma medida eficaz ao seu enfrentamento, uma vez que as práticas podem se deslocar para outros locais da escola que não apresentem supervisão efetiva de adultos ou mesmo as agressões podem se tornar mais sutis/implícitas, o que dificulta ainda mais a identificação pelas autoridades escolares. Nesse sentido, a transmissão de uma mensagem clara de que o bullying é prejudicial a todos os envolvidos e que não confere benefícios aos agressores em termos de status positivo ou poder legítimo pode conferir melhores resultados (Fisher, 2010).

Outra intervenção desenvolvida pelos professores se refere ao encaminhamento para outros profissionais da escola. Por exemplo: "os alunos gostam de apelidar uns aos outros, nem sempre conseguimos resolver. Então, passo para a direção" (P9). A intervenção interdisciplinar constitui importante recurso, especialmente diante de situações mais graves ou complexas que ultrapassam o limite das competências do professor. O que deve ser evitado é a transferência de responsabilidade para a intervenção, pois, além de o professor perder uma oportunidade de atuação no contexto de ocorrência da agressão, pode indiretamente indicar desinteresse e descaso pelos alunos envolvidos (Ahtola et al., 2012).

Os dados sugeriram ainda que, em determinados momentos, a intervenção do professor não ocorre, conforme indica P2: "as agressões acontecem o tempo todo, e, muitas vezes, temos que parar as nossas aulas para refletir sobre a situação. Por isso, algumas situações não são discutidas, pois teríamos que gastar um tempo grande para resolver". Evidencia-se que o papel desempenhado pelos professores investigados também apresenta momentos em que prevalece a pouca implicação, à semelhança do que foi encontrado na pesquisa de São Paulo (Apeoesp, 2013), na qual os participantes acreditavam que a família seria a principal responsável por minimizar a violência na escola, por exemplo.

A probabilidade de um aluno ser alvo de bullying na escola é constituída basicamente por quatro fatores: 1. presença de um agressor motivado, 2. percepção de que certo aluno caracteriza um alvo adequado pelo agressor motivado, 3. ausência de adultos dispostos a intervir e 4. proximidade do aluno-alvo em relação ao agressor motivado e a presença em locais que oportunizem agressões (Boulton et al., 2012). Ante essas considerações, os professores não podem se esquivar de agir diante de todas as ocorrências, pois as vítimas necessitam de sua intervenção, por não apresentarem condições pessoais para autodefesa. Quando os professores conseguem atuações bem-sucedidas, os incidentes de bullying são reduzidos por abrirem brechas ao enten- 
dimento dos alunos de que eles se encontram sob proteção, especialmente as vítimas. Também em relação aos agressores no sentido de que serão responsabilizados pelas agressões que praticarem.

De modo geral, observa-se que algumas das intervenções realizadas pelos professores podem ser consideradas, em certa medida, como adequadas, por exemplo: interromper a aula para intervir no momento em que ocorreu a agressão ou incentivar a turma a refletir sobre a situação ocorrida, visando conscientizar os alunos sobre as consequências negativas do bullying. Todavia, nota-se a descontinuidade nas intervenções por não acontecerem todas as vezes em que se percebe a ocorrência de alguma agressão. Para que os professores possam lidar, de forma mais eficaz, com situações de violência nas turmas, os seguintes fatores são fundamentais: conhecimento mais profundo acerca do bullying, orientações voltadas à intervenção, suporte técnico e infraestrutura organizacional da instituição escolar, e articulação desta com as famílias dos alunos. Porém, isso não implica isenção de responsabilidade em desenvolver atuações mais consistentes e apropriadas, tendo em vista os efeitos danosos da violência sobre o desenvolvimento pessoal e escolar dos alunos.

Nesse sentido, a literatura científica sugere que abordagens fragmentadas ou realizadas com recursos inadequados exercem pouco impacto sobre o bullying. De acordo com Lisboa et al. (2009), é imprescindível refletirmos sobre o papel e a interferência dos diferentes contextos de socialização, a exemplo da família, da escola e da sociedade, na emergência de comportamentos agressivos. Entretanto, na sala de aula, é essencial o papel do professor na construção de ambientes mais seguros e sem violência. Para tanto, a preparação deles é fundamental. A formação em serviço pode ser uma estratégia importante para ajudá-los a superar as dificuldades enfrentadas cotidianamente na sala de aula, pois o modo como entendem os episódios de intimidação, identificam-nos e intervêm neles tem um efeito direto sobre o bem-estar físico, psicológico e social dos alunos.

\section{Referências}

Ahtola, A., Haataja, A., Kärnä, A., Poskiparta, E., \& Salmivalli, C. (2012). For children only? Effects of the KiVa antibullying program on teachers. Teaching and Teacher Education, 28(6), 851-859.

Bardin, L. (2010). Análise de conteúdo. Lisboa: Edições 70.

Boulton, M., Woodmansey, H., Williams, E., Spells, R., Nicholas, B., Laxton, E., Holman, G., \& Duke, E. (2012). Associations between peer bullying and classroom concentration: evidence for mediation by perceived personal safety and relationship with teacher. Educational Psychology, 32(3), 277-294.

Due, P., Holstein, B. E., Lynch, J., Diderichsen, F., Gabhain, S. N., Scheidt, P., \& Currie, C. (2005). Bullying and symptoms among school-aged children: international comparative cross sectional study in 28 countries. European Journal of Public Health, 15(1), 128-132. 
Fisher, R. M. (2010). Bullying escolar no Brasil: relatório final. São Paulo: Ceats, FIA. Recuperado em 7 agosto, 2011, de http://escoladafamilia.fde.sp.gov.br/v2/ Arquivos/pesquisa-bullying escolar no brasil.pdf.

Fung, A. L. (2012). Intervention for aggressive victims of school bullying in Hong Kong: a longitudinal mixed-methods study. Scandinavian Journal of Psychology, 53(4), 360-367.

Kochenderfer-Ladd, B., \& Pelletier, M. E. (2008). Teachers' views and beliefs about bullying: influences on classroom management strategies and students' coping with peer victimization. Journal of School Psychology, 46(2), 431-453.

Lisboa, C., Braga, L. L., \& Ebert, G. (2009). O fenômeno bullying ou vitimização entre pares na atualidade: definições, formas de manifestação e possibilidades de intervenção. Contextos Clínicos, 2, 59-71.

Malta, D. C., Silva, M. A. I., Mello, F. C. M., Monteiro, R. A., Sardinha, L. M. V., Crespo, C., Porto, D. L. (2010). Bullying in Brazilian schools: results from the national school-based health survey (PENSE). Ciência \& Saúde Coletiva, 15(1), 365-376.

Olweus, D. (1994). Bullying at school: basic facts and effects of a school based intervention strategy. Journal of Child Psychology and Psychiatry, 25(3), 1171-1190.

Olweus, D. (2013). School bullying: development and some important challenges. Annual Review of Clinical Psychology, 9(1), 751-780.

Pereira, B., Mendonça, D., Neto, C., Valente, L., \& Smith, P. K. (2004). Bullying in Portuguese schools. School Psychology International, 25(2), 207-222.

Rech, R. R., Halpern, R., Tedesco, A., \& Santos, D. F. (2013). Prevalence and characteristics of victims and perpetrators of bullying. Journal de Pediatria, 89(2), 164-170.

Roth, G., Kanat-Maymon, Y., \& Bibi (2011). Prevention of school bullying: the important role of autonomy-supportive teaching and internalization of pro-social values. British Journal of Educational Psychology, 81(3), 654-666.

Sindicato dos Professores do Ensino Oficial do Estado de São Paulo (2013). Violência nas escolas: o olhar dos professores. São Paulo: Apeoesp.

Skrzypiec, G., Slee, P., Murray-Harvey, R., \& Pereira, B. (2011). School bullying by one or more ways: does it matter and how do students cope? School Psychology International, 32(3), 288-311.

Yoon, J. S., \& Kerber, K. (2003). Bullying: elementary teachers' attitudes and intervention strategies. Research in Education, 69(1), 27-36.

Submissão: 24.8 .2013

Aceitação: 10.8 .2015 